\author{
Audit Teknologi Sistem Informasi Untuk \\ Evaluasi Manajemen Teknologi \\ Informasi \\ Pebriyanti \\ $195100033 \mathrm{P}$ \\ Fakultas Komputer \\ pebriyanti.student@umitra.ac.id
}

\begin{abstract}
Pemanfaatan Teknologi Informasi sebagai pendukung pencapaian tujuan dan sasaran organisasi harus diimbangi dengan keefektifan dan efisiensi pengelolaannya. Maka dari itu, audit TI haruslah dilakukan untuk menjaga keamanan sistem informasi sebagai aset organisasi, untuk mempertahankan integritas informasi yang disimpan dan diolah dan tentu saja untuk meningkatkan keefektifan penggunaan teknologi informasi serta mendukung efisiensi dalam organisasi. Penelitian ini bertujuan untuk melakukan pemetaan terhadap tahap audit TI beserta kontrolnya yang kemudian diaplikasikan pada sebuah organisasi, yaitu Universitas XYZ untuk melihat kinerja TI yang ada. Kerangka kerja yang digunakan sebagai acuan adalah COBIT-ISACA dengan menggunakan 210 detailed control objective yang ada. Penyelenggaraan audit dilakukan dengan menggunakan tahapan-tahapan yang ada pada IT Assurance Guide. Hasil dari evaluasi atau temuan dilakukan analisa root cause sehingga didapat sebuah rekomendasi untuk manajemen TI yang lebih baik lagi.
\end{abstract}

Kata Kunci : Audit Teknologi Sistem Informasi/TI 


\section{A. ENDAHULUAN}

Pemenuhan kebutuhan akan sistem informasi bagi semua jenis organisasi menyebabkan perkembangan sistem informasi yang begitu pesat. Begitu pula dengan perkembangan di sektor pelayanan pendidikan yang dikenal dengan Sistem Informasi Akademik.

Sistem Informasi Akademik merupakan suatu kebutuhan yang mutlak bagi pelayanan pendidikan terutama pada perguruan tinggi, sehingga dapat memberikan kemudahan dalam administrasi bagi perguruan tinggi yang menerapkannya. Dengan adanya Sistem Informasi Akademik dan Sistem Informasi lainnya di universitas XYZ, bukan hanya pelayanan terhadap mahasiswa yang menjadi lebih baik tetapi juga pelayanan untuk seluruh pihak terkait dengan proses akademik yang ada seperti staf pengajar, biro administrasi bahkan orangtua dan alumni. Peranan Sistem Informasi yang signifikan inilah yang tentu saja harus diimbangi dengan pengaturan dan pengelolaan yang tepat sehingga kerugian-kerugian yang mungkin terjadi dapat dihindari. Kerugian yang dimaksud bisa dalam bentuk informasi yang tidak akurat yang disebabkan oleh pemrosesan data yang salah sehingga dapat mempengaruhi pengambilan keputusan yang salah pula. Keamanan asetnya salah satunya adalah data tidak terjaga, integritas data yang tidak dapat dipertahankan, halhal inilah yang dapat mempengaruhi efektifitas dan efisiensi dalam pencapaian tujuan dan strategi organisasi.

Sehubungan dengan alasan tersebut diperlukan adanya sebuah mekanisme kontrol terhadap pengelolaan teknologi informasi [1]. Masalah yang sering timbul di Universitas XYZ adalah adanya kasus kehilangan data, kesalahan dalam pengambilan keputusan, kebocoran data, penyalahgunaan komputer dan nilai investigasi TI yang tinggi tetapi tidak diimbangi dengan pengembalian nilai yang sesuai. Berawal dari sini maka diperlukan sebuah mekanisme kontrol atau audit Sistem Informasi atau audit Teknologi Informasi. Audit SI/TI dalam kerangka kerja COBIT lebih sering disebut dengan istilah IT Assurance ini bukan hanya dapat memberikan evaluasi terhadap keadaan tata kelola Teknologi Informasi di unversitas XYZ tetapi dapat juga memberikan masukan yang dapat digunakan untuk perbaikan pengelolaannya di masa yang akan datang. Tujuan dan manfaat dari penelitian ini adalah (1) Melakukan evaluasi terhadap pengelolaan teknologi informasi atau manajemen teknologi informasi yang ada di universitas XYZ. (2) Hasil yang diperoleh dari kajian ini diharapkan dapat dijadikan landasan dalam pembuatan 
kerangka kerja tata kelola TI yang sesuai dengan standar.

Berdasarkan uraian dari latar belakang permasalahan diatas penulis dapat merumuskan permasalahan penelitian sebagai berikut: (1) Jenis evaluasi manajemen TI yang sesuai untuk organisasi seperti Universitas XYZ. (2) Kontrol objektif yang digunakan dalam melakukan evaluasi.

Penelitian ini difokuskan untuk melakukan evaluasi terhadap pengelolaan teknologi informasi yang mengacu pada proses pelaksanaan di Universitas XYZ dengan menerapkan IT assurance yang berbasis kepada control objective yang ada pada COBIT versi 4.1 [2].

\section{B. PEMBAHASAN / STUDI KASUS}

Dalam melaksanakan audit TI diterapkan metodologi audit TI yang sesuai dengan metodologi yang diajukan oleh IT Assurance Guide: Using COBIT. Tetapi sebelum menentukan pilihan menggunakan COBIT sebagai kerangka kerja audit, dilakukan beberapa pertimbangan diantaranya yaitu dengan melakukan benchmarking antara kerangka kerja audit yang ada seperti Ron Weber [1], Queensland Audit Office dan Jack Champlain [3]. Semua kerangka audit tersebut dipetakan sehingga didapat sebuah kesimpulan bahwa kerangka COBIT adalah kerangka kerja audit yang paling lengkap. Kemudian penulis juga melakukan perbandingan antara COBIT dengan ITIL (Information Technology Infrastructure Library) [4] untuk mendapatkan gambaran yang lebih jelas dalam proses pada domain Delivery and Support.

Dalam melaksanakan evaluasi, dilakukan beberapa langkah, yaitu:

a. Penentuan Rencana Audit Dalam penentuan rencana audit, terdapat langkahlangkah yang dilakukan, yaitu:

1. Memahami visi dan misi dari Universitas XYZ, sasaran, tujuan dan prosesnya.

2. Mengidentifikasi kebijakan, standar, pedoman serta prosedur dari Universitas XYZ.

3. Melakukan analisis resiko.

b. Menentukan lingkup audit dan tujuan audit

Dalam menentukan lingkup audit dan tujuan audit penulis melakukan hal-hal berikut:

1. Menentukan tujuan audit TI.

2. Melakukan pemilihan control objective yang akan digunakan untuk menguji keefektifan dari proses TI yang ada.

3. Mendokumentasikan arsitektur yang ada di Universitas XYZ.

4. Mendefinisikan prosesproses TI yang akan 
dikaji.

5. Mendefinisikan komponen TI yang ada di Universitas XYZ.

c. Melakukan kajian di universitas XYZ

Kajian akan dilakukan dengan menggunakan panduan yang ada dalam melakukan sebuah kajian teknologi informasi/IT assurance guide. Kajian ini meliputi detailed control objective yang disesuaikan dengan keadaan dari Universitas XYZ (berdasar pada high level control objective). Kajian akan dilakukan dengan pendekatan audit yang sudah dibuat. Setelah proses pengkajian selesai tahap berikutnya adalah mendokumentasikan temuantemuan hasil audit.

d. Melakukan analisa hasil audit

Setelah kajian dilakukan, selanjutnya menganalisis temuan-temuan yang didapat. Diharapkan hasil dari tahap analisis ini mendapatkan suatu kesimpulan alasan terjadinya permasalahan serta solusi terhadap permasalahan tersebut.

\section{Tujuan Audit Sistem Informasi}

1. Pengamanan aset. Aset informasi suatu perusahaan seperti perangkat keras (hardware), perangkat lunak (software), sumber daya manusia, dan data harus dijaga dengan sistem pengendalian intern yang baik agar tidak ada penyalahgunaan aset perusahaan.

2. Efektifitas sistem informasi perusahaan memiliki peranan penting dalam proses pengmbilan keputusan. Suatu sistem informasi dapat dikatakan efektif bila sistem informasi tersebut sudah dirancang dengan benar (doing the right thing), telah sesuai dengan kebutuhan user. Informasi yang dibutuhkan oleh para manajer dapat dipenuhi dengan baik.

3. Efisiensi sistem menjadi sangat penting ketika sumber daya kapasitasnya terbatas. Jika cara kerja dari sistem aplikasi komputer menurun maka pihak manajemen harus mengevaluasi apakah efisiensi sistem masih memadai atau harus menambah sumber daya, karena suatu sistem dapat dikatakan efisien jika sistem informasi dapat memnuhi kebutuhan user dengan sumber daya informasi yang minimal. Cara kerja sistem benar (doing thing right).

4. Ketersediaan (Availability) Berhubungan dengan ketersediaan dukungan/layanan teknologi informasi (TI). TI hendaknya dapat mendukung secara kontinyu terhadap proses bisnis kegiatan perusahaan. Makin sering terjadi gangguan (system down) maka berarti tingkat ketersediaan sistem rendah.

5. Kerahasiaaan (Confidentiality) Fokusnya ialah pada proteksi terhadap informasi dan supaya terlindungi dari akses dari pihak yang idak berwenang.

6. Kehandalan (Realibility) Berhubungan dengan 
kesesuaian dan kekuratan bagi manajemen dalam pengolahan organisasi, pelaporan dan pertanggungjawaban.

7. Menjaga integritas data adalah salah satu konsep dasar sistem informasi. Data memiliki atribut-atribut seperti kelengkapan kebenaran dan keakuratan.

\section{Tahapan Audit}

1. Subjek Audit

Tentukan/identifkasi unit/lokasi yang diaudit.

2. Sasaran audit. Tentukan sistem secra spesifik, fungsi atau unit orgainisasi yang akan diperiksa

3. Jangkauan audit. Identifikasi sistem secara spesifik, fungsi atau unit organisasi untuk dimasukkan lingkup pemeriksaan.

4. Rencana pre-audit

a) Identifikasi kebutuhan keahlian teknik dan sumber daya yang diperlukan untuk audit

b) Identifikasi sumber bukti untuk tes atau review seperti fungsi flowchart, kebijakan,

standard prosedur dan kertas kerja audit sebelumnya.

5. Prosedur audit dan langkalangkah pengumpulann bukti audit.
a) Identifikasi dan pilih pendekatan audit untuk memeriksa dan menguji pengendalian intern
b) Identifikasi daftar individu untuk interview

c) Identifikasi dan menghasilkan kebijakan yang berhubungan dengan bagian, standar dan pedoman untuk interview

d) Mengembangakn instrumen audit dan metodologi pengujian dan pemeriksaan kontrol internal

6. Prosedur untuk evaluasi

a) Organisasikan sesuai kondisi dan situasi

b) Identifikasi prosedur evaluasi atas tes efektifitas dan efisiensi sistem, evaluasi kekuatan dari dokumen, kebijakan dan prosedur yang diaudit

7. Laporan hasil audit. Siapkan laporan yang objektif, konsteuktif (bersifat membangun) dan menampung penjelasan audit.

\section{ID SECURITY}

QWTD4452377-ASP-5244107

\section{KESIMPULAN}

Audit Sistem Informasi merupakan suatu proses pengumpulan Dari hasil pengujian terhadap keefektifan kontrol sudah ada kontrol yang berjalan yaitu PO8.1. Quality Management System, PO8.4. Customer Focus, PO8.5 Continuous Improvement dan PO8.6 Quality Measurement, Monitoring and Review, hal itupun karena ada penerapan standarisasi ISO. Kontrol yang lainnya adalah DS5.9. Malicious Software Prevention, Detection and Correction

Di Universitas XYZ tidak ada mekanisme pemantauan dan 
pengevaluasian kinerja yang dilakukan di kedua unit TI (PPS dan Cybernet) hal ini terbukti dari kontrol yang ada pada domain Monitor dan Evaluate yang masih tidak ada sama sekali.

Berdasarkan temuan-temuan yang ada, dapat disimpulkan bahwa manajemen TI yang kurang memadai dikarenakan kurangnya sumber daya manusia yang mengelola

\section{E. DISKUSI}

Saya bersama teman saya bernama Siswanti mendiskusikan tentang Audit Teknologi Sistem Informasi bahwasannya sangatlah penting apabila seorang auditor memiliki keahlian komputer. Karena, tugas seorang auditor itu ialah memeriksa, dalam arti luas bermakna evaluasi terhadap suatu organisasi, sistem, proses, atau produk. Untuk itulah, seorang Auditor dilaksanakan oleh pihak yang kompeten, objektif, dan tidak memihak. Tujuannya adalah untuk melakukan verifikasi bahwa subjek dari audit telah diselesaikan atau berjalan sesuai dengan standar, regulasi, dan praktik yang telah disetujui dan diterima. Selain itu, seorang auditor harus memahami sistem pengendalian manajemen yang ada di perusahaan tersebut, agar dapat menilai apakah pengendalian yang ada di perusahaan sudah memadai atau belum. Rekomendasi yang disampaikan merupakan hasil analisis terhadap temuantemuan yang didapat dari pengujian keefektifan kontrol dan hasil pengujian terhadap output kontrol.

Dalam memberikan rekomendasi, dibagi menjadi tiga jangka waktu pencapaian, yaitu rekomendasi

jangka pendek yang berkaitan dengan hal-hal yang harus dengan segera dilakukan oleh Universitas XYZ agar prosesproses TI yang ada masih tetap berjalan dengan baik. Untuk rekomendasi jangka menengah, dilakukan pengklasifikasian berdasarkan perencanaan strategis di unit TI, sementara untuk rekomendasi jangka panjang diberikan rekomendasi yang berkenaan dengan kebijakan Universitas setingkat dengan kebijakan organisasinya.

\section{A. REFERENCE}

[1] O. M. Febriani and A. S. Putra, "Sistem Informasi Monitoring Inventori Barang Pada Balai Riset Standardisasi Industri Bandar Lampung," J. Inform., vol. 13, no. 1, pp. 90-98, 2014.

[2] A. S. Putra, "Paperplain: Execution Fundamental CreateApplication With Borland Delphi 7.0 University Of Mitra Indonesia," 2018.

[3] A. S. Putra, "2018 Artikel Struktur Data, Audit Dan Jaringan Komputer," 2018.

[4] A. S. Putra, "ALIAS MANAGER USED IN DATABASE DESKTOP STUDI CASE DB DEMOS." 
[5]

A. $\mathrm{S}$.

Putra, "COMPREHENSIVE

SET OF PROFESSIONAL

FOR

DISTRIBUTE COMPUTING."

[6] A. S. Putra, "DATA ORIENTED RECOGNITION IN BORLAND DELPHI 7.0."

[7] A. S. Putra, "EMBARCADERO DELPHI XE 2 IN GPU- POWERED FIREMONKEY APPLICATION."

[8] A. S. Putra, "HAK ATAS KEKAYAAN INTELEKTUAL DALAM

DUNIA TEKNOLOGY BERBASIS REVOLUSI INDUSTRI 4.0."

[9] A. S. Putra, "IMPLEMENTASI

PERATURAN

PERUNDANGAN UU. NO 31

TAHUN 2000

TENTANG DESAIN

INDUSTRI

BERBASIS

INFORMATION

TECHNOLOGY."

[10] A. S.

Putra, "IMPLEMENTATION OF PARADOX DBASE."

[11] A. S

Putra, "IMPLEMENTATION OF TRADE SECRET CASE STUDY SAMSUNG MOBILE PHONE."

[12] A.

S.

Putra, "IMPLEMENTATION PATENT FOR APPLICATION WEB BASED CASE STUDI

WWW. PUBLIKLAMPUNG. COM."
SYSTEM FIRST TO INVENT IN DIGITALLY INDUSTRY."

[14] A. S. Putra, "MANUAL REPORT \& INTEGRATED DEVELOPMENT

ENVIRONMENT BORLAND DELPHI 7.0."

[15] A. S. Putra, "PATENT AS RELEVAN SUPPORT RESEARCH.”

[16] A. S. Putra, "PATENT FOR RESEARCH STUDY CASE OF APPLE. Inc."

[17] A. S. Putra, "PATENT PROTECTION FOR APPLICATION INVENT."

[18] A. S. Putra, "QUICK REPORT IN PROPERTY PROGRAMMING."

[19] A. S. Putra, "REVIEW CIRCUIT LAYOUT COMPONENT

REQUIREMENT ON ASUS NOTEBOOK."

[20] A. S. Putra, "REVIEW TRADEMARK PATENT FOR INDUSTRIAL TECHNOLOGY BASED 4.0."

[21] A. S. Putra, "TOOLBAR COMPONENT PALLETTE IN OBJECT ORIENTED PROGRAMMING."

[22] A. S. Putra, "WORKING DIRECTORY SET FOR PARADOX 7."

[23] A. S. Putra, "ZQUERY CONNECTION

IMPLEMENTED

PROGRAMMING STUDI CASE PT. BANK BCA Tbk."

[24] A. S. Putra, D. R. Aryanti, and I. Hartati, "Metode SAW (Simple Additive Weighting) sebagai Sistem Pendukung Keputusan Guru Berprestasi (Studi Kasus: SMK Global Surya)," in 
Prosiding Seminar Nasional Darmajaya, 2018, vol. 1, no. 1, pp. 85-97.

[25] A. S. Putra and O. M. Febriani, "Knowledge

Management Online Application in PDAM Lampung Province," in Prosiding

International conference on Information Technology and Business (ICITB), 2018, pp. 181-187.

[26] A. S. Putra, O. M. Febriani, and B. Bachry, "Implementasi Genetic Fuzzy System Untuk Mengidentifikasi Hasil Curian Kendaraan Bermotor Di Polda Lampung," SIMADA (Jurnal Sist. Inf. dan Manaj. Basis Data), vol. 1, no. 1, pp. 21-30, 2018.

[27] A. S. Putra, H. Sukri, and K. Zuhri, "Sistem Monitoring Realtime Jaringan Irigasi Desa (JIDES) Dengan Konsep Jaringan Sensor Nirkabel," IJEIS (Indonesian J. Electron. Instrum. Syst., vol. 8, no. 2, pp. 221-232.

[28] D. P. Sari, O. M. Febriani, and A.

S. Putra, "Perancangan Sistem Informasi SDM Berprestasi pada SD Global Surya," in Prosiding Seminar Nasional Darmajaya, 2018, vol. 1, no. 1, pp. 289-294. 